\title{
STUDI MINAT MEMBACA SISWA MIN 12 BEREUEN- ACEH
}

\author{
Srie Faizah Lisnasari
}

sriefaizah2502@gmail.com

\begin{abstract}
This study aims to explore further information about the factors that influence the low interest in scholarships at the MIN 12 Bereuen-Aceh School. The population of this study was students MIN 12 Bireuen class VI. The sampling technique is done using the simple random sampling method. The data collection technique used in this study is the Inventory of Student Interest in Safran Model (Safran Students Interest). The results showed that from 32 respondents the following data were obtained: (1) Interest in reading students MIN 12 Bireuen-Aceh, generally included in the medium category with details: 18 Orang $(54.54 \%)$ often went to the library, 13 people (39.39\%) sometimes to the library and only 2 people (6.06\%) always go to the library; (2) Students visit the library: 19 people (57.57\%) sometimes, 14 people $(42.42 \%)$ always and 1 person (3.03\%) never go to the library; (3) The frequency of student visits to the library is generally 1-3 times in 1 week, which is 31 people (93.93\%) from the sample and; (4) visiting the library to search for or read books if: a) there are assignments given by the teacher which are 15 people $(45.45 \%), 6$ people (18.18\%) take advantage of free time to read books or intense library visits and only 1 person (3.03\%) because of hobbies.
\end{abstract}

Keywords: Study, Reading Interest, MIN 12 Bireuen

\begin{abstract}
ABSTRAK
Penelitian ini bertujuan menggali informasi lebih jauh tentang faktor-faktor yang mempengaruhi rendahnya minat bacasiswa di Sekolah MIN 12 Bereuen-Aceh. Populasi penelitian ini adalah siswa MIN 12 Bireuen kelas VI. Teknik pengambilan sampel dilakukan dinging menggunakan metode pengambilan sampel acak sederhana (simple random sampling). Teknik pengumpulan data yang digunakan dalam penelitian ini adalah Inventori Minat Siswa Model Safran (Safran Students Interest). Hasil Penelitian menunjukkan bahwa dari 32 responden diperoleh data sebagai berikut: (1) Minat membaca siswa MIN 12 Bireuen-Aceh, secara umum termasuk ke dalam kategori sedang dengan perincian: 18 0rang (54.54\%) sering ke perpustakaan, 13 orang (39.39\%) kadang-kadang ke perpustakaan dan hanya 2 orang (6.06\%) selalu ke perpustakaan; (2) Siswanya mengunjungi perpustakaan : 19 orang (57.57\%) kadang-kadang, 14 orang (42.42\%) selalu dan 1 orang (3.03\%) tidak pernah ke perpustakaan; (3) Frekuensi kunjungan siswa ke perpustakaaan umumnya 1-3 kali dalam 1 minggu yaitu sebanyak 31 orang $(93.93 \%)$ dari sampel dan; (4) berkunjung keperpustakaan untuk mencari atau membaca buku jika: a) ada tugas yang diberikan oleh guru yakni 15 orang $(45.45 \%), 6$ orang $(18.18 \%)$ memanfaatkan waktu luang untuk membaca buku atau intens berkunjung keperpustakaan dan hanya 1 orang $(3.03 \%)$ karena hobi.
\end{abstract}

Kata Kunci: Studi, Minat Baca, MIN 12 Bireuen 


\section{PENDAHULUAN}

Ilmu pengetahuan dan teknologi sangat cepat berubah dan mengalami perkembangan. Agar tidak ketinggalan, manusia diharapkan dapat mengikuti perkembangan tersebut dengan mengetahui lebih banyak informasi. Sebagian besar informasi yang diperoleh adalah dari kegiatan membaca.

Data dalam dokumen UNDP dalam Human Development Report 2000, bahwa angka melek huruf orang dewasa di Indonesia hanya 65,5 persen. Sedangkan Malaysia sudah mencapai 86,4 persen, dan negara-negara maju seperti Australia, Jepang, Inggris, Jerman, dan AS umumnya sudah mencapai 99,0 persen. Dengan kondisi seperti itu, maka tidak heran bila kualitas pendidikan di Indonesia juga buruk. Dalam hal pendidikan, survey The Political and Economic Risk Country (PERC), sebuah lembaga konsultan di Singapura, pada akhir 2001, menempatkan Indonesia di urutan ke-12 dari 12 negara di Asia yang diteliti. Berdasarkan survei UNESCO padatahun 2011. Hasil survey lembaga UNESCO (United Nation Education Society and Cultural Organization) adatahun 2011, juga menemukan fakta bahwa indeks membaca masyarakat Indonesia betul-betul rendah yaitu baru sekitar 0,001 . Artinya dari seribu penduduk, hanya ada satu orang yang masih memiliki minat baca tinggi. Angka ini masih sangat jauh dibandingkan dinging angka minat baca di
Amerika dan Singapura, apalagi Jepang. Amerika memiliki indeks membaca 0,45 dan Singapura memiliki indeks 0,55. Jepang memiliki indeks 17 komasekian. Bahkan budaya baca masyarakat Indonesia berada di urutan ke-38 dari 39 negara dan merupakan yang paling rendah di kawasan ASEAN.

Aktivitas membaca sudah sebaiknya ditanamkan sejak dini. Mulai dari usia balita sampai dewasa. Tak terkecuali di Madrasah Ibtidaiyah Negeri 12 Bireuen aktivitas membaca siswanya dapat menjadi salah satu tempat kajian karena kota Bireuen-Aceh sendiri merupakan kota yang dinobatkan sebagai kota Literasi. Selama ini kegiatan membaca di sekolah hanya dilakukan dalam rangka proses belajar mengajar dan untuk menyelesaikan tugas-tugas yang diberikan guru. Masih berada pada taraf dasar kegiatan membaca. Sebenarnya membaca sudah seharusnya menjadi bagian dari kegiatan mencari informasi terkini dan terupdate untuk mengikuti perkembangan ilmu pengetahuan dan teknologi. Sehingga bila keadaan seperti itu sudah berlangsung dengan baik, maka akan dapat diharapkan meningkatnya pengetahuan warga negara sehingga dapat meningkatkan taraf tingkat berfikir dan pada akhirnya dapat meningkatkan taraf kehidupan dan kesejahteraan masyarakat. Berdasarkan uraian tersebut, penulis melakukan penelitian dengan judul: Studi Minat 
Srie Faizah Lisnasari : Studi Minat Membaca Siswa ...

Membaca Siswa Madrasah Ibtidaiyah Negeri 12 Bereuen- Aceh

\section{METODE PENELITIAN}

Penelitian ini dibuat dengan tujuan menggali informasi lebih jauh tentang faktor-faktor yang mempengaruhi rendahnya minat baca siswa dalam aktivitasnya di sekolah. Penelitian ini diharapkan dapat menjadi masukan bagi guru, siswa dan pihak perpustakaan di Sekolah MIN 12 Bereuen-Aceh untuk membantu meningkatkan minat membaca siswanya. Penelitian ini dilaksanakan pada tanggal 5-6 September 2018 bertempat di MIN 12 Bireuen-Aceh. Populasi penelitian ini adalah siswa MIN 12 Bireuen kelas VI yang berjumlah 6 kelas dan sampel untuk keperluan penelitian yang diambil hanya 1 kelas saja yaitu Kelas VI (1). Teknik pengambilan sampel dilakukan dinging menggunakan metode pengambilan sampel acak sederhana (simple random sampling). Penelitian diskriptif adalah penelitian yang memberikan gambaran tentang suatu permasalahan. Metode ini digunakan untuk memperoleh data tentang minat siswa untuk membaca di MIN.

\section{HASIL PENELITIAN DAN PEMBAHASAN}

Hal yang terpenting dalam penelitian adalah instrumen yang digunakan untuk mengukur variabel. Dalam penelitian ini terdiri dari satu variabel yaitu minat siswa. Instrumen yang digunakan dalam penelitian ini menggunakan kuesioner. Metode yang digunakan untuk penelitian ini adalah dengan cara memberikan kuesioner yang berisi daftar pertanyaan yang diberikan kepada mahasiswa.

\section{Pembahasan}

Hasil penelitian menunjukkan bahwa dari 32 responden diperoleh data sebagai berikut: (1) Minat membaca siswa MIN 12 BireuenAceh, secara umum termasuk kedalam kategori sedang dengan perincian: 18 orang $(54,54 \%)$ sering ke perpustakaan, 13 orang $(39,39 \%)$ kadang-kadang ke perpustakaan dan hanya 2 orang $(6,06 \%)$ selalu ke perpustakaan.

Dalam membaca diperlukan minat yang datang dari dalam diri sendiri. Minat dan perhatian yang tinggi terhadap bacaan akan dapat menghasilkan pemahaman yang baik terhadap isi bacaan jika dibandingkan dengan orang yang memiliki minat rendah. Minat yang tumbuh dalam diri seseorang tergantung pula pada tingkat intelektualnya. Semakin tinggi tingkat intelektual seseorang, biasanya dia juga akan memiliki minat yang tinggi terhadap sesuatu. Dorongan untuk memperoleh sesuatu akan menumbuhkan minat yang besar pula. Hal ini sejalan dengan pendapat Lilawati (1988) bahwa minat membaca adalah suatu perhatian yang kuat dan mendalam disertai dengan perasaan senang terhadap kegiatan membaca. Minat baca bukanlah sesuatu yang dibawa sejak lahir tetapi harus dipupuk dan 
dibina sejak dini. Demikian juga sejalan dengan pendapat Dewi (1997).

Dengan membaca, kebutuhan seseorang akan suatu informasi akan dapat terpenuhi. Sumber bacaan dapat diperoleh dari mana aja, tidak terkecuali perpustakaan. Minat mengunjungi perpustakaan untuk tujuan membaca buku pada siswa MIN 12 Bireuen Banda Aceh tergolong sedang, dapat dilihat dari 32 sampel siswa yang dijadikan subjek penelitian terdapat 18 orang sering ke perpustakaan, 13 orang kadang-kadang ke perpustakaan dan 2 orang lagi selalu ke perpustakaan.

Dalam hal frekuensi siswa mengunjungi perpustakaan : 19 orang $(57,57 \%)$ kadang-kadang, 14 orang $(42,42 \%)$ selalu dan 1 orang $(3,03 \%)$ tidak pernah ke perpustakaan; Banyaknya kunjungan siswa ke perpustakaan tentunya dengan tujuan yang bermacammacam. Ada yang membaca di perpustakaan untuk mengisi waktu, untuk menambah pengetahuan, atau untuk mencari informasi. Sebagian besar dari sampel penelitian hanya kadang-kadang datang ke perpustakaan, yang selalu datang ke perpustakaan hanya 14 orang dan malah ada juga 1 orang yang tidak pernah mendatangi perpustakaan di sekolahnya. Walaupun hanya 1 orang yang tidak pernah mendatangi perpustakaan, hal ini menjadi fenomena yang menarik untuk dikaji lebih jauh sebab-sebab apa yang membuat siswa tersebut tidak pernah mengunjungi perpustakaan.
Hal ini sejalan dengan pengelompokan frekuensi kunjungan siswa ke perpustakaan yang umumnyahanya 1-3 kali dalam 1 minggu yaitu sebanyak 31 orang (93,93\%)dari sampel. Jadi dari 32 siswa sebanyak 14 orang selalu ke perpustakaan yaitu 3-5 kali seminggu berkunjung. Sedangkan selebihnya kadang-kadang berkunjung yaitu 1-3 kali semingu.

Sejalan dengan freuensi kunjungan, umumnya siswa yang berkunjung ke perpustakaan hanya mencari buku untuk mengerjakan tugas yang diberikan guru, yaitu sebanyak 15 orang $(45,45 \%)$, sedangkan 6 orang $(18.18 \%)$ berkunjung hanya untuk memanfaatkan waktu luang untuk membaca buku atau intens berkunjung keperpustakaan dan hanya 1 orang $(3,03 \%)$ karena hobby; (5) Jenis buku yang biasa dicari siswa di perpustakaan MIN 12 Bireuen-Aceh umumnya adalah buku mata pelajaran yakni sebanyak 16 orang (50\%), membaca novel 14 orang $(43 \%)$ dan 1 orang membaca majalah.

\section{SIMPULAN}

Dari hasil angket yang telah disebar pada tanggal 5 September 2018 kepada 32 responden diperoleh data bahwa (1) minat membaca siswa MIN 12 Bireuen-Aceh, secara umum termasuk kedalam kategori sedang; (2) Siswa hanya mengunjungi perpustakaan kadangkadang saja; (3) Frekuensi kunjungan siswa ke perpustakaaan umumnya 1- 
3 kali dalam 1 minggudan; (4) berkunjung keperpustakaan untuk mencari atau membaca buku jika ada tugas yang diberikan oleh guru dan hanya sebagian kecil siswa yang memanfaatkan waktu luang untuk membaca buku atau intens berkunjung keperpustakaan. (5) buku yang biasa dicari siswa di perpustakaan MIN 12 Bireuen-Aceh adalah buku mata pelajaran.

\section{DAFTAR RUJUKAN}

Ancok J. 1989. Validitas dan Reabilitas Instrument Penelitian. Di dalam: Singarimbun M, editor. Metode Penelitian Survey. Jakarta: LP3ES.

Arikunto, Suharsimi. 2002. Prosedur Penelitian, Suatu Pendekatan Praktek. Jakarta: PT. Rineka Cipta

Azam, Syukur Rammatullah. 2005. Problematika anak kampus. Qurani Media Pustaka: Yogyakarta

De Porter, Bobbi \& Mike Hernachi. 2003. Quantum Learning: membiasakan belajar nyaman dan menenangkan. Bandung: Kaifa.
Franz, Kurt \& Benhard Meier. 1983. MembinaMinat Baca.

Bandung: RemadjaKarya

Nurhadi. 1989. Bagaimana Meningkatkan Kemampuan Membaca. Bandung: CV Sinar Baru Offset

Sugiyono. 2007. Metode penelitian kuantitatif dan $R \& D$. Bandung: Alfa beta.

Siregar, A.R. 2008. Strategi Mengembngkan Kebiasaan Membaca Mahasiswa. Diunduh tanggal 15 Februari 2014.

http://repository.usu.ac.id/bitsr eam/123456789/1892/1/08E00 519.pdf

Utomo, A.S. 1998. Upaya Perpustakaan Menumbuhkan Minat Baca Masyarakat, Buletin FKP2T, Th. III. no.2, Juli-Desember. Jakarta.

Sudarsana, Undang, Bastino. 2011. Pembinaan Minat Baca. Jakarta: Universitas Terbuka.

Hasan, M. Iqbal. 2002. Pokok-pokok Materi Metodologi Penelitian dan Aplikasinya. Bogor: Ghalia Indonesia. 